\title{
Characterization of the Reactive and Dissociative Behavior of Transition Metal Oxide Cluster Ions in the Gas Phase
}

\author{
Simin Maleknia and Jennifer Brodbelt \\ Department of Chemistry, University of Texas at Austin, Austin, Texas, USA \\ Keith Pope \\ IBM T. J. Watson Research Center, Yorktown Heights, New York, USA
}

The reactive and dissociative behavior of molybdenum and tungsten oxide cluster ions has been studied in the gas phase using a triple quadrupole mass spectrometer. Cluster ions $\left(\mathrm{MO}_{3}\right)_{\mathrm{n}}^{-}$were formed via a simple thermal desorption/electron capture negative ionization method, and their structures were characterized by collision-activated dissociation (CAD). Typically, the clusters fragment by losses of neutral $\left(\mathrm{MO}_{3}\right)$ units. Reactions of the oxide cluster ions with ethylene oxide, cyclohexene oxide, ethylene sulfide, cyclohexene sulfide, 2,3-butanedione, and 2,4-pentanedione were examined, and product ions were characterized by CAD. The clusters react with ethylene oxide by addition of ethylene oxide or net addition of oxygen, whereas the clusters react with ethylene sulfide via net addition of one or two sulfur atoms. Reactions of the clusters with the diones result in addition of one or two dione units, in some cases with dehydration. (J Am Soc Mass Spectrom 1991, 2, 212-219)

$\mathrm{T}$ The increasing interest in gas-phase studies of transition metal oxides stems in part from the use of oxides as catalysts in various oxidation processes [1, 2]. For example, molybdenum-containing catalysts have been used in ammoxidation of hydrocarbons [3], demetalation [4], selective oxidation of olefins [5], various photooxidation reactions [6, 7], and hydrotreating processes such as hydrodesulfurization and hydrodenitrogenation [8-12]. The latter two processes are particularly important in the oil industry because there is an increasing trend toward large-scale refining of heavy crude oils containing high percentages of sulfur and nitrogen. Such oxide catalysts are also useful for epoxidation of olefins [13]. Additionally, it has been demonstrated that methanol is oxidized to formaldehyde over $\mathrm{MoO}_{3}$ in a process in which any Mo that is not coordinatively saturated may act as an active site [14]. The mechanisms of these oxidation reactions often involve oxygen atom transfer from the oxides with participation by oxometal groups [15].

The factors that most greatly influence the catalytic properties of the oxides include structural coordinalion and oxidation stale. One example lughlighting the importance of the latter involves the homologation and metathesis of ethylene by $\mathrm{MoO}_{3}$ [16]. The

Address reprint requests to lennifer Brodbelt, Department of Chemistry, University of Texas at Austin, Austin, TX 78712-1167. active sites for homologation require a more reduced $\mathrm{MoO}_{x}$ species (like $\mathrm{Mo}^{4+}$ ) than for metathesis, the latter proceeding via metal alkylidene and metallacyclobutane intermediates. Moreover, it was recently proved that it is the lattice oxygen ions of $\mathrm{MoO}_{3}$, the most active catalyst for propene oxidation to acrolein. that are inserted into the organics undergoing oxidation, and not the oxygen atoms that may adsorb on the catalyst surface [17].

Another interest in transition metal oxides has developed from their use as dielectric or insulating materials in electronic applications [18]. Some oxides, such as $\mathrm{WO}_{3}$, are intrinsically semiconducting and are being used in new solid state device and sensor technology. For example, thin films of semiconducting material have shown remarkable sensitivities as gas sensors for propane, $\mathrm{NH}_{3}, \mathrm{H}_{2}, \mathrm{H}_{2} \mathrm{~S}$, and for reducing agents $[19,20]$. In many cases, the mechanism of activity depends on the extraction and infusion of carriers from the oxide by oxygen adsorbed and/or organic species oxidized at the surface.

There have been numerous studies of metal clusters, and more recently metal oxide clusters, using various mass spectrometric techniques [21, 22]. Increasingly, attention has been focused on the characterization of the reactive behavior of these clusters in the gas phase. For example, alkene oxidation by transition metal oxides was studied [23], ion/molecule reactions of $\mathrm{Co} /$ oxygen cluster ions were investigated 
[24], and the reactivities of a range of bare metal clusters including $\mathrm{Al}_{\mathrm{n}}^{+}$[25], $\mathrm{Pt}_{\mathrm{n}}^{+}$[26], $\mathrm{Fe}_{\mathrm{n}}^{+}$[27], $\mathrm{Nb}_{\mathrm{n}}^{+}$ [28], CuFe ${ }^{+}\left[29\right.$, and $\mathrm{Ni}_{\mathrm{n}}^{+}[30$ ] with neutral substrates such as $\mathrm{CO}, \mathrm{N}_{2}, \mathrm{O}_{2}, \mathrm{CH}_{4}, \mathrm{C}_{2} \mathrm{H}_{4}$, and $\mathrm{NH}_{3}$ were examined. Correlations of ion abundances with structural configuration have also been drawn: the cluster ion distributions for selected metal oxides was shown to be dependent on the electron configuration of the metal in the oxide [31]. Further studies of gas-phase metal oxide clusters are of interest not only because they can yield information of intrinsic heterogeneous catalytic mechanisms, but also because clusters afford a natural array of size-selected related structures.

The aims of this article are to (1) demonstrate the viability of producing an array of clusters by using a simple, inexpensive thermal desorption method and (2) present a survey of the interesting reactive behavior of two size-selected series of metal oxide clusters. Initial work was reported previously on the production of molybdenum and tungsten oxide cluster ions by using a simple thermal desorption method to generate clusters in the gas phase and the determination of their dissociative behavior by using low energy collision-activated dissociation (CAD) techniques [32]. These results were followed with an investigation of the reactive behavior of the oxides. The ion/molecule reaction chemistry of these oxides was examined for two reasons. First, certain neutral reagents were chosen to probe the intrinsic reactive behavior and product formation of the size-selected clusters. Second, both structural and energy differences of ions can be distinguished on the basis of their reactive behavior with selected compounds [33]. The reactive species of particular interest are ethylene oxide, cyclohexene oxide, ethylene sulfide, cyclohexene sulfide, 2,3butanedione, and 2,4-pentanedione (acetylacetone). Low energy collision activation was used to compare the relative dissociative behavior of the product ions. No suitable compounds with known structures exist. so the reactive and dissociative behavior of the cluster ions cannot be compared to the behavior of model compounds. However, collisional activation is still valuable as a tool for comparing relative differences in dissociative behavior within a related series of ions.

\section{Experimental}

Metal oxide clusters are formed via desorption from a direct evaporation probe and electron capture negative ionization. A Finnigan Triple Stage Quadrupole (TSQ-70) (Finnigan-MAT, San Jose, CA) was operated in the negative chemical ionization mode at a source temperature of $80^{\circ} \mathrm{C}$. Argon was used as the buffer gas to promote thermal electron production at a manifold pressure of $4 \times 10^{-6}$ torr (approximately 1200 mtorr ion source pressure). Samples were applied to a platinum or rhenium filament from a methanol suspension, and ions were produced by increasing the flament current until sufficient signal intensity was
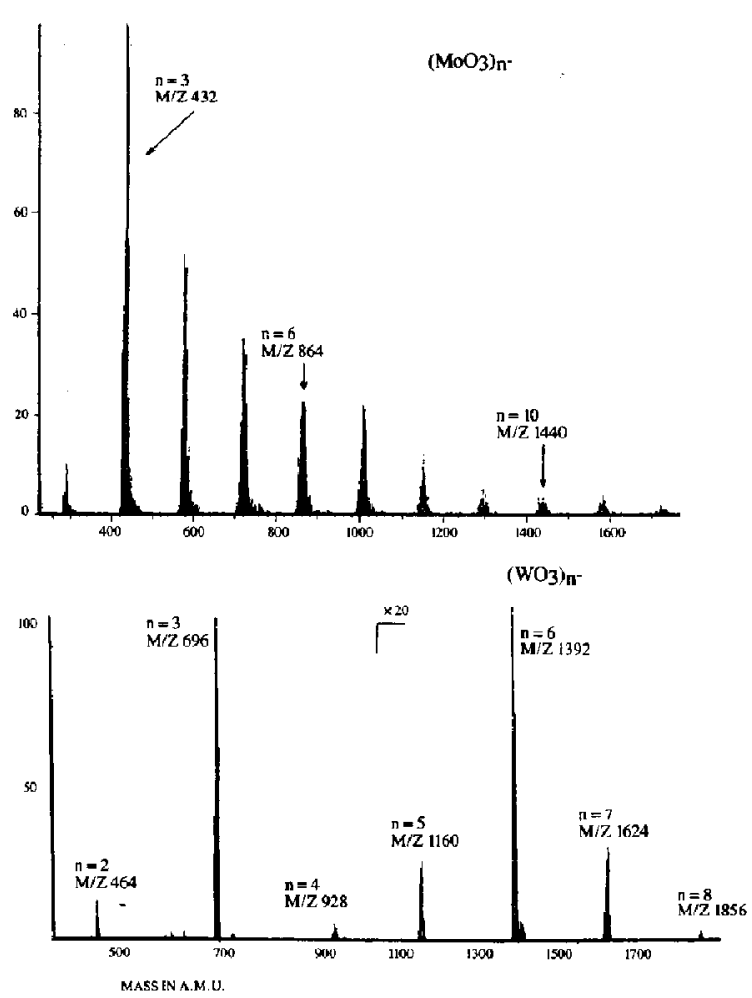

Figure 1. Electron capture negative ionization mass spectra of $\left(\mathrm{MoO}_{3}\right)_{\mathbf{n}}^{-}$and $\left(\mathrm{WO}_{3}\right)_{n}^{-}$clusters.

obtained. For CAD experiments, the collision cell pressure was 1 mtorr of argon, corresponding to multiple collision conditions. Collision energy was defined by the potential difference between the ion source and the central quadrupole. Breakdown curves were obtained by programming the collision cell offset potential to step between 60 and $160 \mathrm{~V}$ by $20 \mathrm{~V}$ per step. Collision energies below $60 \mathrm{~V}$ did not induce dissociation. A dual metering inlet valve was used for the introduction of the reagent gas and reactive gases or liquids. All compounds were purchased from Aldrich Chemical (Milwaukee, WI) and used without further purification.

\section{Results and Discussion}

\section{Negative Ionization Mass Spectra and Collision- Activated Dissociation}

The clusters were generated by using a thermal desorption probe. This is a remarkably simple method for producing an array of clusters, and does not involve the use of a laser for desorption and/or ionization, nor does it involve the use of a supersonic expansion. Negative electron capture mass spectra of the metal oxide clusters, $\left(\mathrm{MoO}_{3}\right)_{\mathbf{n}}^{-}$and $\left(\mathrm{WO}_{3}\right)_{\mathbf{n}}^{-}$, are shown in Figure 1. The $\left(\mathrm{MoO}_{3}\right)_{n}^{-}$clusters were observed up to a range of $2000 \mathrm{u}$, where $\mathrm{n}=13$, and the $\left(\mathrm{WO}_{3}\right)_{\mathrm{n}}^{-}$ 
clusters were observed up to $\mathbf{n}=\mathbf{8}$. The monomer, $\mathrm{MO}_{3}$, was not observed for either metal, and the dimer gave a relatively weak signal, although the relative abundances of the higher mass cluster ions decreased essentially monotonically with increasing n. Typically trimer and hexamer species have the greatest abundances.

Often collisional activation experiments are used to compare the dissociative behavior of one ion having an unknown structure to the dissociative behavior of model compounds. This allows general structural correlations to be made. However, collisional activation experiments may also be used to compare the dissociative behavior of a related series of ions, such as a mass-selected array of clusters, without the use of model compounds. It is well documented that ion activation may induce isomerization or rearrangement of an energized parent ion prior to fragmentation [34]. If experimental conditions are held constant, however, then reproducible differences in CAD spectra may indicate structural differences within the series of related ions or patterns in fragmentation behavior. For this reason, the fragmentation behavior of the $\left(\mathrm{MoO}_{3}\right)_{n}$ clusters was studied by generating breakdown curves via variable kinetic energy collisional activation. The curves for the clusters from $n=3-7$ are shown in Figure 2, and the energy axes have not been corrected for the laboratory reference frame. A dominant feature of the fragmentation pathways is loss of an array of $\left(\mathrm{MoO}_{3}\right)_{\mathrm{n}}$ units. These losses may be dimers, trimers, or tetramers, or they may be sequential losses of $\mathrm{MoO}_{3}$ units. Because the structural identities of the neutrals eliminated during the dissociative processes are not known, the distinction of whether the cluster ions fragment by losing sequential oxide units or by cleavage of a single $\left(\mathrm{MoO}_{3}\right)_{\mathrm{n}}$ unit cannot be made. Losses of oxygen, $\mathrm{Mo}, \mathrm{MoO}$, or $\mathrm{MoO}_{2}$ were never observed. Once the cluster size exceeds $n=5$, only total losses of neutrals larger than $2\left(\mathrm{MoO}_{3}\right)$ are observed, while loss of a monomer unit is only observed for the smaller $(n=3,4)$ clusters. For the cluster sizes $n=4-7$, the favored dissociative pathways result in formation of $\left(\mathrm{MoO}_{3}\right)_{2}^{-}$and $\left(\mathrm{MoO}_{3}\right)_{3}^{-}$, suggesting that the dimer and trimer species have special stabilities. The $\left(\mathrm{WO}_{3}\right)_{n}$ clusters behave qualitatively in the same fashion: losses of neutral dimer and trimer units predominate, whereas loss of a single oxide unit is either absent or highly unfavored. The overall fragmentation scheme for the $\left(\mathrm{MoO}_{3}\right)_{\mathbf{n}}$ clusters, $\mathbf{n}=3-7$. is presented in Figure 3.

\section{Ion / Molecule Reactions with Sulfur- and Oxygen- Containing Compounds}

Ethylene oxide was chosen as a reactive species because metal oxides have been used as catalysts for epoxidations of alkenes. Presumably, the mechanism of oxidation involves transfer of an oxygen atom from the surface of the oxide to the coordinated or ad-
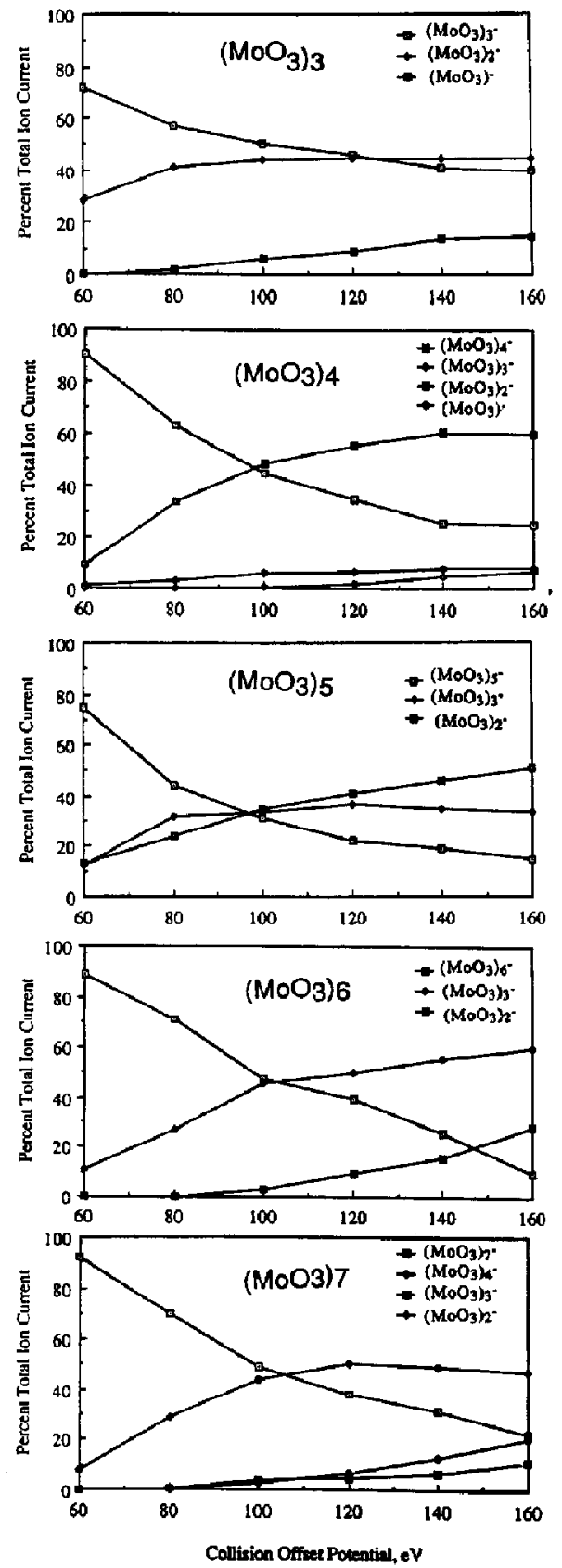

Figure 2. Energy-resolved breakdown curves for $\left(\mathrm{MoO}_{3}\right)_{\mathrm{n}}^{-}$.

sorbed alkene species. There exists considerable ongoing controversy concerning the mechanism for the elimination of ethylene from ethylene oxide and from ethylene sulfide on metals. For example, it has been shown that the complex $\mathrm{Li}_{2} \mathrm{WCl}_{6}$ reacts with substituted ethylene oxide via epoxide ring opening to form an oxametallacyclobutane [35]. The oxametallacyclobutane presumably then undergoes $\mathrm{C}-\mathrm{W}$ and 


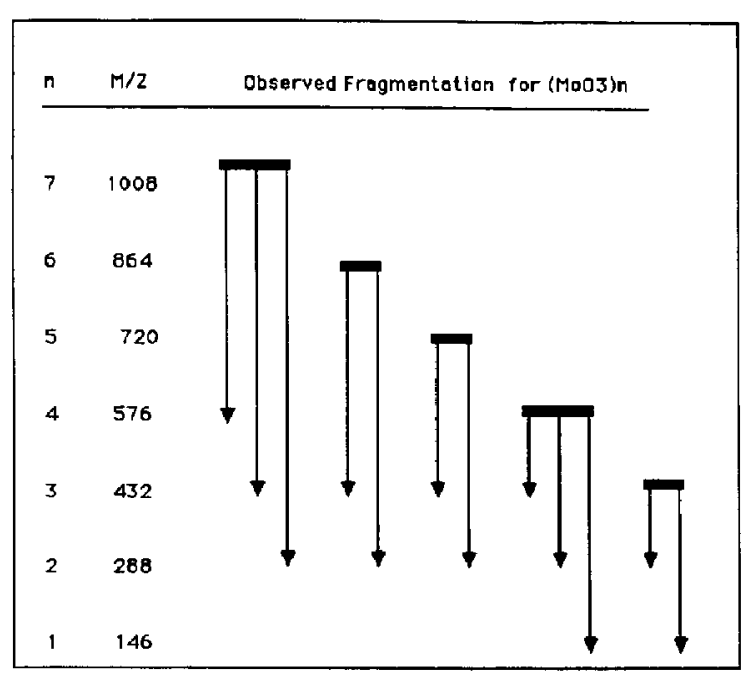

Figure 3. Fragmentation scheme for collision-activated dissociation of $\left(\mathrm{MoO}_{3}\right)_{n}^{--}$.

$\mathrm{C}-\mathrm{O}$ bond cleavages, producing an alkene and a tungsten-oxygen complex. Alternatively, the reaction may occur by a concerted process. The latter was proposed for the reaction of ethylene sulfide on molybdenum [36]. Calculations for ethylene sulfide reactions on both complexes and at surfaces, however, suggest that the concerted mechanism is more energetically favorable at a surface than for a complex [36]. Addilionally, different reactivities of ethylene oxide and ethylene sulfide on metals were observed, due in part to the different strengths of $\mathrm{C}-\mathrm{O}$ and $\mathrm{C}-\mathrm{S}$ bonds [37]. The $\mathrm{C}-\mathrm{O}$ bond in ethylene oxide is stronger, and less energy is required to decompose ethylene sulfide to ethylene and sulfur than for the analogous process for ethylene oxide.

Therefore, it was our interest to examine the intrinsic reactive behavior of the ionic oxide clusters with ethylene oxide (EtO) and ethylene sulfide (EtS). First, ethylene oxide was introduced into the ion source, and the resulting product ions are shown in Figure 4 for the $\left(\mathrm{WO}_{3}\right)_{\mathrm{n}}$ series. One immediately striking feature is the huge difference in relative abundances of adduct formation for the different cluster sizes. For $\mathbf{n}=2$ or 3 , only small abundances of $\left(\mathrm{WO}_{3}\right)_{\mathrm{n}}$-EtO adducts are observed, whereas for $n=4$ the $\left(\mathrm{WO}_{3}\right)_{4}$ EtO adduct ion is abundant, and for $n=6$ the abundance of the adduct ion exceeds that of the metal oxide cluster. The odd- $n$ cluster adduct ions ( $n=5$ and $n=7$ ) are of small abundances. Only for $n=4$ is the oxygen addition adduct more abundant than the ethylene oxide adduct, perhaps indicating that the geometry of the $n=4$ cluster in some way assists in the elimination of ethylene, unlike the $n=6$ cluster in which expulsion of ethylene is clearly disfavored.

Structural characterization of the adducts was done by using collisional activation at a range of collision energies. A representative case is shown in Figure 5 for the $\left(\mathrm{WO}_{3}\right)_{4} / \mathrm{EtO}$ adduct. At moderate collision energies, the adduct ion fragments by loss of $\mathrm{C}_{2} \mathrm{H}_{4} \mathrm{O}$ (likely as ethylene oxide) or by loss of ethylene. The latter result is particularly intriguing because it supports the suggestion that the metal oxide/ethylene oxide adduct is oriented in such a way that the epoxide oxygen is bonded to a metal center, and therefore the metal oxide is capable of abstracting a solitary oxygen atom. At higher collision energies, dissociation by loss of oxide cluster units is also observed. Additionally, dissociation to an oxide dimer with one extra oxygen is observed, but dissociation to an oxide trimer or monomer with one extra oxygen is not observed. The fact that only selective dissociation channels occur with retention of the oxygen unit implies that the ethylene oxide addition may occur at a specific site of the cluster. In general, all the metal oxide/ethylene oxide adducts dissociate predominantly via loss of 28 u (like as ethylene).

A comparison of the CAD behavior of $\left(\mathrm{WO}_{3}\right)_{4}$-EtO and $\left(\mathrm{WO}_{3}\right)_{6}-\mathrm{EtO}$ is also informative. Whereas the $\mathbf{n}=$ 4 cluster adduct dissociates predominantly by either loss of EtO or ethylene, the $n=6$ cluster dissociates only by loss of ethylene to form the $\left(\mathrm{WO}_{3}\right)_{6}-\mathrm{O}$ species. Bare $\left(\mathrm{WO}_{3}\right)_{6}$ product ions are never observed even at higher collision energies. This clearly indicates a distinction between the cluster sizes, possibly due to the differences in cluster structures, in electronic state densities, or in frontier orbital energies [38], or the more subtle structural changes due to bond-stretch isomerism [39]. The outcome is that the different cluster sizes demonstrate different abilities to bind oxygen. In the present case, the $n=6$ cluster apparently binds the oxygen atom more strongly than the $\mathrm{n}=4$ cluster.

To probe the generality of the capability of metal oxide clusters to abstract oxygen from epoxide species, we also examined the reactive and dissociative behavior of the $\left(\mathrm{WO}_{3}\right)_{\mathrm{n}}$ clusters with cyclohexene oxide $(\mathrm{CyO})$. The mass spectrum of the products is shown

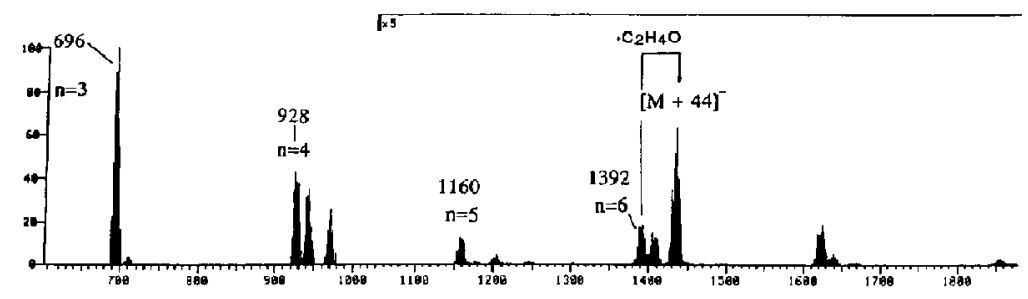

Figure 4. Mass spectrum of the products of the reaction between ethylene oxide and $\left(\mathrm{WO}_{3}\right)_{n}$. 


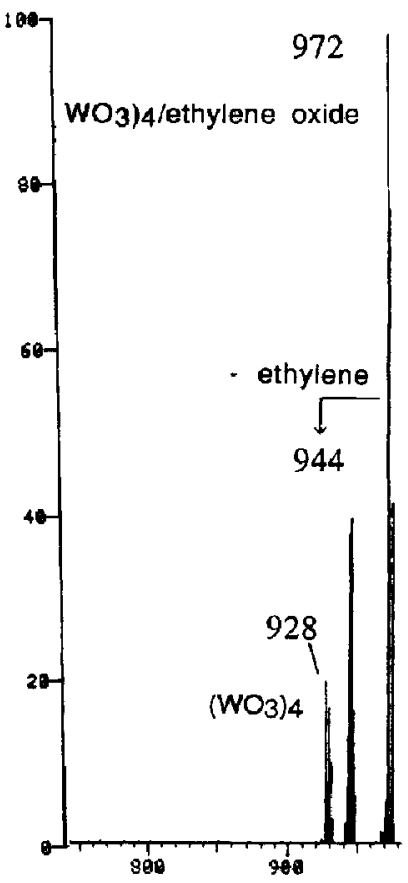

Figare 5. Collision-activaled dissociation spectrum of $\left(\mathrm{WO}_{3}\right)_{4}$ /ethylene oxide at $60 \mathrm{eV}$ collision energy.

in Table 1. In this case, the $n-4$ and $n-6$ clusters again show the greatest relative propensity for adduct formation; however, the $\mathrm{n}=3$ cluster does form adducts (in contrast to the ethylene oxide reactions). With cyclohexene oxide as the reactive substrate, the abundances of the adducts for both $n=4$ and $n=6$ exceeds that of the bare metal oxide cluster. Also, compared to the ethylene oxide adduct data, a greater relative proportion of the adducts exist as oxygen addition species (via loss of neutral cyclohexene) than as cyclohexene oxide adducts. This latter observation presumably reflects the reduced strength of the $\mathrm{C}-\mathrm{O}$ bonds in cyclohexene oxide as compared to ethylene oxide. Collision activation of the $\left(\mathrm{WO}_{3}\right)_{4} /$ cyclohexene oxide cluster indicates that this adduct ion dissociates predominantly to $\left(\mathrm{WO}_{3}\right)_{4}^{-}$(85\% of the ion current) via loss of cyclohexene oxide and to $\left(\mathrm{WO}_{3}\right)_{4} / \mathrm{O}^{-}(15 \%$ of the ion current) by elimination of cyclohexene. Thus, oxygen atom abstraction from more bulky epoxide ligands by the metal oxide clusters is possible.

Similar studies were performed by using ethylene
Table 1. Relative product distribution of reactions of cyclohexene oxide and $(\mathrm{WO} 3)_{n}{ }^{2}$

\begin{tabular}{lcccc}
\hline$n$ & $\begin{array}{l}\text { Scaling } \\
\text { factor }\end{array}$ & $\left(W_{3}\right)_{n}$ & $\left(W O_{3}\right)_{n} / O$ & $\left(W_{3}\right)_{n} / C y O$ \\
\hline \hline 3 & 1 & 0.85 & 0.01 & 0.15 \\
4 & 5 & 0.15 & 0.35 & 0.50 \\
5 & 10 & 0.80 & 0.05 & 0.15 \\
6 & 10 & 0.10 & 0.65 & 0.25 \\
\hline
\end{tabular}

${ }^{a}$ For each cluster size, the product abundances are expressed as the fraction of the tatal ion current for that size.

${ }^{b}$ The scaling factor indicates the overall distribution of cluster sizes.

sulfide and cyclohexene sulfide instead of ethylene oxide and cyclohexene oxide as the reactive gases. A representative spectrum for the adducts produced in the source from $\left(\mathrm{WO}_{3}\right)_{n}$ and ethylene sulfide is shown in Figure 6. One striking difference is obvious. Unlike the ethylene oxide reactions in which adducts of entire ethylene oxide units with $\left(\mathrm{WO}_{3}\right)_{\mathrm{n}}$ were formed, adducts due to the addition of ethylene sulfide units are not observed. Instead, clusters with addition of one or in some cases two sulfur atoms are formed. The abundances of the $n=5,7$ cluster adducts are small, as is the case for the ethylene oxide results, and the abundances of the $n=4,6$ adducts are large. Interestingly, the $n=4$ cluster shows predominant addition of two sulfur atoms whereas the $n=6$ cluster shows only significant addition of one sulfur atom. This absence of ethylene sulfide adducts and presence of sulfur atom adducts (as compared to the ethylene oxide reactions) is consistent with the assumption that the lower $\mathrm{C}-\mathrm{S}$ bond energy than $\mathrm{C}-\mathrm{O}$ bond energy (estimated as $20 \mathrm{kcal} / \mathrm{mole}$ difference [37]) is an important factor in determining the efficiencies of catalytic transformations. This mimics the tendency for desulfurization of ethylene sulfide via intramolecular elimination on single crystal transition metal surfaces. The dissociation behavior of the $\mathrm{n}=3$ cluster/sulfur adduct is shown in Figure 7. This adduct dissociates via loss of any combination of $\left(\mathrm{WO}_{3}\right)_{n}$ and sulfur units.

The product distribution observed from reaction of cyclohexene sulfide with $\left(\mathrm{WO}_{3}\right)_{\mathrm{n}}$ is shown in Table 2 . The $n=4$ and $n=6$ cluster adducts are most abundant, and again $n=4$ shows addition of two sulfur atoms whereas $n=6$ favors addition of one sulfur atom. When the $\left(\mathrm{WO}_{3}\right)_{3} / \mathrm{S}$ adduct is activated, it dissociates via loss of sulfur, and also produces the
Figure 6. Mass spectrum of the products of the reaction between ethylene sulfide and $\left(\mathrm{WO}_{3}\right)_{\mathbf{n}}$.

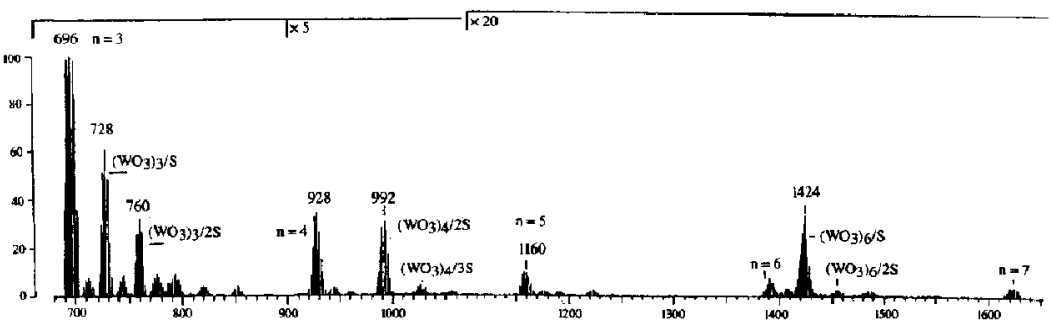



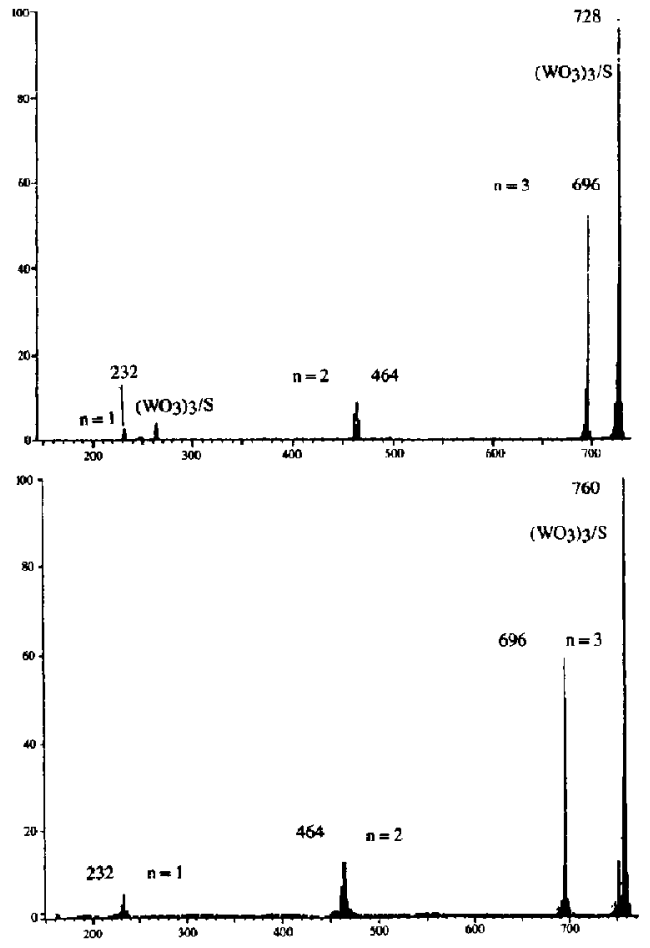

Figure 7. Collision-activated dissociation spectrum of $\left(\mathrm{WO}_{3}\right)_{3} / \mathrm{S}$ and $\left(\mathrm{WO}_{3}\right)_{3} / 2 \mathrm{~S}$.

fragment $\left(\mathrm{WO}_{3}\right) / \mathrm{S}$. Alternatively, when the $\left(\mathrm{WO}_{3}\right)_{3} / 2 \mathrm{~S}$ adduct is collisionally activated, it dissociates only via loss of both sulfur atoms, not by single sulfur atom loss. This suggests that the sulfur atoms are linked by interatomic bonding interactions while attached to the oxide cluster. Losses of $\left(\mathrm{WO}_{3}\right)$ units are also observed.

\section{Ion / Molecule Reactions with Diones}

Acetylacetone was selected as a reactive probe because of its well-characterized properties as a metal chelating agent. The product distribution resulting
Table 2. Relative product distribution from reactions of cyclohexene sulfide and $\left(\mathrm{WO}_{3}\right)_{n}{ }^{a}$

\begin{tabular}{lcccc}
\hline$n$ & $\begin{array}{l}\text { Scaling } \\
\text { factor }^{\mathrm{b}}\end{array}$ & $\left(W O_{3}\right)_{\mathrm{n}}$ & $\left(W O_{3}\right)_{n} / \mathrm{S}$ & $\left(W O_{3}\right)_{n} / 2 S$ \\
\hline \hline 2 & 1 & 0.90 & 0.10 & 0 \\
3 & 1 & 0.85 & 0.10 & 0.05 \\
4 & 2 & 0.80 & 0.05 & 0.15 \\
5 & 20 & 0.95 & 0.05 & 0 \\
6 & 20 & 0.35 & 0.60 & 0.05 \\
7 & 20 & 1.00 & 0 & 0 \\
\hline
\end{tabular}

${ }^{a}$ For each cluster size, the product abundances are expressed as the fraction of the total ion current for that size.

${ }^{b}$ The scaling factor indicates the overall distribution of cluster sizes.

Table 3. Relative product distribution for reactions of $\left(\mathrm{WO}_{3}\right)_{\mathbf{n}}$ and 2,4-pentanedione ${ }^{\mathrm{a}}$

\begin{tabular}{lccccc}
\hline $\mathrm{n}$ & $\begin{array}{c}\text { Scaling } \\
\text { factor }^{\mathrm{b}}\end{array}$ & $\left(\mathrm{WO}_{3}\right)_{\mathrm{n}}$ & $\begin{array}{c}\left(\mathrm{WO} \mathrm{O}_{3} \mathrm{H}_{\mathrm{n}}\right. \\
+82\end{array}$ & $\begin{array}{c}\left(\mathrm{WO} \mathrm{O}_{\mathrm{n}}\right. \\
+100\end{array}$ & $\begin{array}{c}\left(\mathrm{WO}_{3}\right)_{\mathrm{n}} \\
+182\end{array}$ \\
\hline \hline 2 & 1 & 0.65 & 0.05 & 0.15 & 0.15 \\
3 & 1 & 0.15 & 0.10 & 0.20 & 0.55 \\
4 & 1 & 0.01 & 0.05 & 0.80 & 0.15 \\
5 & 10 & 0.05 & 0.05 & 0.45 & 0.45 \\
6 & 10 & 0.10 & 0.05 & 0.30 & 0.55 \\
7 & 10 & 0.25 & 0.05 & 0.45 & 0.25 \\
\hline
\end{tabular}

a For each cluster size, the product abundances are expressed as the fraction of the total ion current for that size.

The scaling factor indicates the overall distribution of cluster sizes.

from reactions of $\left(\mathrm{WO}_{3}\right)_{\mathrm{n}}$ with acetylacetone are shown in Table 3. Several observations are apparent. First, to some extent all of the sizes of the metal oxide clusters demonstrate some reactivity. Second, the size selectivity toward adduct formation does not obey a clearly defined trend based on odd or even cluster size. Third, products are consistently observed at [ $\mathrm{M}$ $+82]^{-},[M+100]^{-}$, and $[M+182]^{-}$. Presumably the $\left[\mathrm{M}+\mathrm{82}^{-}\right.$product is an acetylacetone/metal oxide adduct that has undergone dehydration, while $[\mathrm{M}+$ 182] " represents a metal oxide cluster with two acetylacetone ligands that has undergone dehydra-

Table 4. Distribution of daughter ions from collisionally activated $\left(\mathrm{WO}_{3}\right)_{3} /$

2,4-pentanedione adducts ${ }^{\text {a }}$

\begin{tabular}{|c|c|c|c|c|c|}
\hline \multirow[t]{2}{*}{ Parent ion } & \multicolumn{5}{|c|}{ Daughter ions } \\
\hline & $\left(\mathrm{WO}_{3}\right)_{2}$ & $\left(\mathrm{WO}_{3}\right)_{2} / \mathrm{O}$ & $\left(\mathrm{WO}_{3}\right)_{3}$ & $\left(W O_{3}\right)_{3} / O$ & $\left(\mathrm{WO}_{3}\right)_{3} / 82$ \\
\hline $\begin{array}{l}{\left[\left(\mathrm{WO}_{3}\right)_{3} /(\mathrm{acac})_{2}\right.} \\
\left.-\mathrm{H}_{2} \mathrm{O}\right] \\
(\mathrm{M}+182)^{-}\end{array}$ & 0.10 & 0.30 & 0.15 & 0 & 0.45 \\
\hline $\begin{array}{l}{\left[\left(\mathrm{WO}_{3}\right)_{3} / \mathrm{acac}\right]} \\
(\mathrm{M}+100)^{-}\end{array}$ & 0.05 & 0.05 & 0.80 & 0.01 & 0.10 \\
\hline $\begin{array}{l}\mathrm{I}\left(\mathrm{WO}_{3}\right)_{3} / \mathrm{acac} \\
\left.-\mathrm{H}_{2} \mathrm{O}\right] \\
(\mathrm{M}+82)^{-}\end{array}$ & 0.10 & 0.10 & 0.80 & 0 & 0 \\
\hline
\end{tabular}

${ }^{\circ}$ Collision energy was $100 \mathrm{eV}$. 
Table 5. Product distribution from reactions of 2,3butanedione and $\left(\mathrm{WO}_{3}\right)_{n}{ }^{a}$

\begin{tabular}{cccc}
\hline $\mathrm{n}$ & $\begin{array}{c}\text { Scaling } \\
\text { factor }^{\mathrm{b}}\end{array}$ & $\left(\mathrm{WO}_{3}\right)_{n}$ & $\begin{array}{c}\left(\mathrm{WO}_{3}\right)_{n} / \\
\text { butanedione }\end{array}$ \\
\hline \hline 3 & 1 & 0.25 & 0.75 \\
4 & 1 & 0.50 & 0.50 \\
5 & 1 & 0.70 & 0.30 \\
6 & 10 & 0.15 & 0.85 \\
7 & 10 & 0.95 & 0.05 \\
\hline
\end{tabular}

a For each cluster size, the product abundances are expressed as the fraction of the total ion current for that size.

'The scaling factor indicates the overall distribution of cluster sizes.

tion. For $\mathbf{n} \geq 3$, the abundances of the adducts exceed the abundances of the bare cluster in all cases. Additionally, if $n=3$ or $n=6$, a propensity for addition of two acetylacetone units is observed.

Collision-activated dissociation of these three adduct species reveals some further structural information (see Table 4 ). In the case of $[M+100]^{-}$or $[\mathrm{M}+182]^{-}$, loss of neutral acetylacetone is favored, whereas for the $[\mathrm{M}+82]^{-}$ion, dissociation to produce the bare metal cluster is predominant. Furthermore, the $\left(\mathrm{WO}_{3}\right)_{3}$ /acetylacetone adduct ion also dissociates via loss of water. All the cluster adducts dissociate to some extent to $\left(\mathrm{WO}_{3}\right)_{2} / \mathrm{O}^{-}$. The $\left(\mathrm{MoO}_{3}\right)_{\mathrm{n}}$ ions also formed $[\mathrm{M}+82]^{-},[\mathrm{M}+100]^{-}$, and $[\mathrm{M}+$ $182]^{-}$adducts, and the fragmentation behavior of these species is analogous to the tungsten cluster behavior.

A comparison of the chelating capabilities of acetylacetone and 2,3-butanedione was also done. Similar to the reactive trends shown for acetylacetone/metal oxide clusters, the greatest relative abundances of adduct ions are produced for $\left(\mathrm{WO}_{3}\right)_{3} /$ butanedione and for $\left(\mathrm{WO}_{3}\right)_{6} /$ butanedione (Table 5). Without exception, the major dissociative channel of the adducts is loss of butanedione. In no case does any dehydration occur; this is attributed to the limited source of alpha-hydrogens available for migration to the oxygen for formation of a water molecule.

\section{Conclusions}

Both $\left(\mathrm{MoO}_{3}\right)_{\mathrm{n}}^{-}$and $\left(\mathrm{WO}_{3}\right)_{\mathrm{n}}^{-}$clusters dissociate predominantly via losses of small cluster units, resulting in stable dimers or trimers. The clusters react with ethylene oxide via addition of ethylene oxide or addition of oxygen. Collisional activation of these adducts indicates that dissociation by loss of ethylene oxide or ethylene is favored, and this suggests that the ethylene oxide is bonded to the cluster in such a way that the cluster-oxygen interaction is stronger than the $\mathrm{C}$ $-\mathrm{O}$ bonds in ethylene oxide. Analogous behavior in which oxygen abstraction may occur is observed for cluster reactions with cyclohexene oxide. Ion $/ \mathrm{mole}$ cule reactions with sulfur-containing substrates reveal that addition of one or two sulfur atoms to the clus- ters is possible, yet adducts of the clusters with entire cyclohexene sulfide or ethylene sulfide are never observed. Possibly this absence is because the $\mathrm{C}-\mathrm{S}$ bonds are weaker than the $\mathrm{C}-\mathrm{O}$ bonds, and therefore the elimination of an unsaturated hydrocarbon neutral (such as ethylene or cyclohexene) via cleavage of the $\mathrm{C}-\mathrm{S}$ bonds is easier. For these sulfide and oxide reactions, both $\mathrm{n}=4$ and $\mathrm{n}=6$ cluster sizes show greater relative product ion abundances than the other cluster sizes. Reactions with 2,3-butanedione and 2,4-pentanedione produce a much more complex array of product ions, including various additions and dehydrations. In general, the $\left(\mathrm{MoO}_{3}\right)_{n}$ clusters produce smaller abundances of adducts than the $\left(\mathrm{WO}_{3}\right)_{\mathrm{n}}$ clusters. The differences in the reactive behavior of the various sizes of cluster ions may indicate either a structural or energy difference in the clusters, and this will be probed by examining alternative methods of forming the cluster ions prior to reactions.

\section{Acknowledgments}

This work was supported by the Welch Foundation (F-1155), the National Science Foundation (Post-doctoral Starter Grant), and the Society of Analytical Chemists' of Pittsburgh.

\section{References}

1. Gates, B. C.; Guczi, L.; Knozinger, H. Metal Clusters in Catalysis; Elsevier: New York, 1986.

2. Grasselli, R. K.; Burrington, J. D. In Advances in Catalysis; Eley, D. D.; Pines, H.; Weisz, P. B., Eds.; Academic: New York, 1981; pp. 30, 131.

3. Reddy, B. M.; Narsimha, K.; Sivaraj, Ch.; Roa, P. K. Applicd Cataiysis 1989, 55, L1.

4. Bielanski, A; Haber, J. Catal. Rev,-Sci. Eng. 1979, 19(1).

5. Fierro, J.; Garcia De La Banda, J. F.; Catal. Rev.-Sci. Eng. $1986,28,265$

6. Awad, M. K.; Anderson, A. B. J. Am. Chem. Soc. 1990, 112, 1603.

7. Renneke, R. F.; Hill, C. L. J. Am. Chem. Soc. 1989, 110, 5461 .

8. Grange, P. Catal. Rev.-Sci. Eng. 1980, 21, 135.

9. Laine, R. M. Catal. Rev.-Sci. Eng. 1983, 25, 459.

10. Chianclli, R. R. Catal. Rev. Sci. Eng. 1984, 26, 361.

11. Prins, R.; De Beer, V. H. J.; Somorjai, G. A. Catal. Rev.-Sci. Eng. 1989, 3I, 1.

12. Furimsky, E. Catal. Rev.-Sci. Eng. 1980, 22, 371.

13. Parshall, G. W. The Applications and Chemistry of Catalysis by Soluble Transition Metal Complexes; Wiley-Interscience: New York, 1980.

14. Cheng, W.; Chowdhry, U.; Ferretti, A.; Firment, L.; Groff, P.; Machiels, C.; McCarron, E.; Ohuchi, F.; Staley, R.; Sleight, A. Heterogeneous Catalysis; Shapiro, B., Ed,; Texas A \& M, 1984; p. 165.

15. Sheldon, R.; Kochi, J.; Metal Catalyzed Oxidation of Organic Compounds; Academic: NY, 1981; Chap. 6.

16. Suzuki, T.; Gotoh, H. Applied Catalysis 1989, 50, 15.

17. Lopez Nieto, J. M.; Kremenic, G.; Martinez-Alonoso, A. Tascon, J. M. D. J. Mat. Science 1990, 25, 289.

18. Madou, M. J.; Morrison, S. R. Cherrical Sensing with Solid State Devices; Academic: CA, 1989.

19. Treitinger, L.; Voit, H. NTG Fachberichte 79, 1982, 3, 24

20. Shaver, P. J. Appl. Phys. Lett. 1967, 11, 255. 
21. Wheeler, R. G.; Laihing, K.; Wilson, W. L.; Duncan, M. A. Chem. Phys. Lett. 1986, 131, 8.

22. Nieman, G. C.; Parks, E. K.; Richtsmeier, S. C.; Liu, K.; Pobo, L. G.; Riley, S. J. High Temp. Science 1986, 22, 115.

23. Kang, H.; Beauchamp, J. L. J. Am. Chem. Soc. 1986, 108, 5663.

24. Freas, R. B.; Dunlap, B. I.; Waite, B. A.; Campana, J. E. J. Chem. Phys. 1987, 86, 1276.

25. Jarrold. M. F.; Bower, J. E. I. Am. Chem. Soc. 1988, 110, 6706.

26. Trevor, D. J.; Whetten, R. L.; Cox, D. M.; Kaldor, A. J. Am. Chem. Soc. 1985, 107, 518.

27. Parks, E. K.; Weiller, B. H.; Bechthold, P. S,; Hoffman, W. F.; Nieman, G. C.; Pobo, L. G.; Riley, S. J. J. Chem. Phys. 1988, 88, 1622 .

28. Zakin, M. R,; Brickman, R. O.; Cox, D. M.; Kaldor, A. J. Chem. Soc. 1988, 88, 5943.

29. Tews, E. C.; Freiser, B. S. J. Am. Chem. Soc. 1987, 109, 4433.

30. Magnera, T.; David, D.; Michl, J. J. Am. Chem. Soc. 1987, $109,936$.
31. Michiels, E.; Gijbels, R. Anal. Chem. 1984, 56, 1115.

32. Maleknia, S. D.; Hogan, J. D.; Laude, D. A.; Pope, K. R.; Procetings of the 37th ASMS Cunference un Mass Spectrometry and Allied Topics, Miami Beach, FL, May 1989, pp. 155-156.

33. Franklin, J., Ed. Ion-Molecule Reactions; Plenum: New York, 1979.

34. Busch, K.; Glish, G., McLuckey, S. Mass Spectrometry/Mass Spectrometry: Techriques and Applications of Tandem Mass Spectrometry; VCH: New York, 1988; Chap. 4, and references cited therein.

35. Sharpless, K. B.; Teranishi, A. Y.; Backvall, Jan-E. I. Am. Chem. Soc. 1977, 99, 3120.

36. Seratin, J, G.; Friend, C. M. I. Am. Chem. Soc. 1989, 111, 6019.

37. Roberts, J. T.; Friend, C. M. Surface Science 1988, 202, 405.

38. Cotton, A.; Wilkinson, G. Advanced horganic Chemistry, 5th ed.; John Wiley: New York, 1988.

39. Jean, Y.; Lledos, A.; Burdett, J,; Hoffmann, R. J. Am. Chem. Soc. 1988, $110,4506$. 